\title{
Prevalence of Hepatitis B Virus Infection in a Population Exposed to Biological Risk
}

\author{
Andrea Trevisan and Paolo Paruzzolo \\ Department of Environmental Medicine and Public Health, University of Padova
}

\begin{abstract}
Prevalence of Hepatitis B Virus Infection in a Population Exposed to Biological Risk: Andrea Trevisan, et al. Department of Environmental Medicine and Public Health, University of PadovaThe prevalence of hepatitis $B$ virus infection was investigated in 1,221 subjects (809 exposed to different degrees of biological risk and 412 presumably not exposed personnel) employed in Padua University. The population was subdivided in four groups according to no, low and occasional, intermediate, even though continuous, and high exposure to biological risk. A past history of hepatitis $B$ virus infection was detected in $10.0 \%$ of subjects $(8.8 \%$ had positive hepatitis B antibodies, $1.1 \%$ positive hepatitis $B$ surface antigens and $0.2 \%$ positive hepatitis $B$ enveloped antigen). Seroprevalence of positive hepatitis $B$ antibodies increased with age $(p<0.001)$ but was not related with sex. No significantly high prevalence of hepatitis $B$ virus infection was found among the groups, but excluding vaccinated subjects $(333,27.3 \%)$, the prevalence was significantly higher in intermediate $(p<0.025)$ and the high $(p<0.001)$ risk groups when compared with the other two groups, other than in high compared with the intermediate risk group $(p<0.05)$. The results show low prevalence $(10.0 \%)$ of hepatitis $B$ virus infection in the examined population, but increasing according to the risk extent.

(J Occup Health 2000; 42: 341-344)
\end{abstract}

Key words: Biological risk, Hepatitis B infection

Hepatitis B virus (HBV) infection is one of the most remarkable biological risk in hospital personnel owing to exposure to human fluids ${ }^{1-15}$.

Vaccination reduced the risk of HBV infection, but in Italy vaccination is only suggested, not compulsory by law, for workers exposed to biological risk. Since 1991, Italian law requires vaccination for all newborns and

Received March 13, 2000; Accepted Sept 20, 2000

Correspondence 10: A. Trevisan, Department of Environmental Medicine and Public Health, University of Padova, Via Giustiniani 2, 1-35128 Padova, Italy children up to and including the twelfth year of life. On the other hand, biological risk at work is regulated by European Community leading (CEE directive 90/679) and, in Italy, by legislative decree $626 / 94$, that suggests the use of all available preventive devices to reduce the risk.

In the Italian population a decrease in the prevalence of HBV infection was observed until $1994^{12)}$, with high prevalence in males and in subjects 15-24 yr old, related to the abuse of parenteral drugs in this population. On the other hand, the clinical symptoms of HBV infection appear with low frequency, as suggested by the discovery of positive antibodies (and antigens) in a number of subjects without anamnestic infection. In addition, the application of vaccination is still low in subjects exposed to biological hazard, and non responders to vaccine probably increase the number of subjects susceptible to HBV infection.

The present research aims to investigate the immunological conditions related to $\mathrm{HBV}$ and liver function in a population employed in Padua University, operating in the biomedical field, at different degrees of biological risk. Since the study had not the opportunity to investigate the immunological conditions before starting the current job career, it lacks the ability to pinpoint when subjects became infected. On the other hand, it is possible to assume that the small number of $\mathrm{HB}$ surface (HBs) antigen positive subjects were infected in infancy.

\section{Materials and Methods}

HBV markers (antibodies and antigens) were evaluated in 1,221 subjects ( 809 exposed to different degrees of biological risk and 412 presumably not exposed subjects) employed in Padua University and who submitted to health surveillance for physical, chemical and biological risk according to ltalian legislative decree 626/94.

The characteristics of the subjects are summarized in Table 1. The length of exposure was between 3 and 40 yr. The subjects were subdivided according to sex, age 
Table 1. Characteristics of the subjects investigated for the immunological status against HBV infection

\begin{tabular}{|c|c|c|c|c|c|c|c|}
\hline & N. & $\begin{array}{c}\text { Age } \\
\text { mean }(S E)\end{array}$ & $\begin{array}{l}\text { Age } \\
\text { range }\end{array}$ & $\begin{array}{l}\mathrm{M} \\
\mathrm{N}\end{array}$ & $\begin{array}{l}\mathrm{F} \\
\mathrm{N}\end{array}$ & $\begin{array}{c}\leq 40 \mathrm{yr} \\
\mathrm{N} .\end{array}$ & $\begin{array}{c}>40 \mathrm{yr} \\
\mathrm{N} .\end{array}$ \\
\hline Total & 1221 & $41.8(0.3)$ & $22-73$ & & & 608 & 613 \\
\hline Males & 812 & $43.8(0.4)$ & $22-73$ & & & & \\
\hline Females & 409 & $38.0(0.5)$ & $24-67$ & & & & \\
\hline R0 $0^{\mathrm{a}}$ & 412 & $44.0(0.5)$ & $22-71$ & 357 & 55 & 180 & 232 \\
\hline $\mathrm{R} 1^{\mathrm{h}}$ & 262 & $43.0(0.6)$ & $24-71$ & 141 & 121 & 122 & 140 \\
\hline $\mathrm{R} 2^{\mathrm{c}}$ & 312 & $39.7(0.5)$ & $23-69$ & 174 & 138 & 172 & 140 \\
\hline $\mathrm{R}^{\mathrm{d}}$ & 235 & $39.6(0.7)$ & $24-73$ & 140 & 95 & 134 & 101 \\
\hline
\end{tabular}

Legend: "supposed not exposed group: chemists, physicists, agronomists, mineralogists and geologists; 'low risk: biologists, biochemists and pharmacists; cintermediate risk: pharmacologists and physicians; "high risk: surgeons, obstetricians, midwives, pathologists, microbiologists and workers employed in preparation of histological slides.

( $\leq$ or $>40$ years of age), and risk group. Four risk groups were classified as follows: risk group 0 (R0, 412 subjects) comprises workers employed in a laboratory without the possibility of pollution with biological materials and includes chemists, physicists, agronomists, mineralogists and geologists. R0 group was the presumably not exposed group. Risk group 1 (R1, low, 262 subjects) was composed of workers exposed to low and occasional contact with human biological materials, for example, biologists, biochemists and pharmacists. Risk group 2 (R2, intermediate, 312 subjects) was composed of workers exposed to continuous contact with human fluids, for example, pharmacologists (the difference from pharmacists was in the greater use of human fluids) and physicians, but with low possibility of accidental injury or large skin contamination. Risk group 3 (R3, high, 235 subjects) was composed of workers exposed to high biological risk, such as surgeons, obstetricians, midwives and pathologists (workers exposed to accidental injury by sharp instruments), microbiologists and workers employed in the preparation of histological slides. The risk groups were classified according to the frequency of contact with human biological fluids or contaminated instruments, after an investigation of each laboratory or surgical room.

All subjects were submitted (by a physician) to a complete interview on health history, clinical examination, determination of HBV antibodies and antigens by the E.I.A. method (Sorin, Saluggia, TO, Italy for envelope antigens and antibodies and Organon Teknika S.p.A, Rome, Italy, for the others). No subject declared intravenous drug abuse and only one had received a number of blood transfusions after a road accident. Sexual behavior was not investigated owing to the impossibility of keeping the questionnaire anonymous (all data reported are anonymous according to Italian Privacy Law 675/96).
Statistics: prevalence of positive HBV antibodies was studied by means of $\chi^{2}$ distribution with Yates correction; significance was from $p<0.05$. Statistical analysis was performed by means of Statgraphics 4.0 version.

\section{Results}

HBV markers evaluated in 809 subjects exposed to different degrees of biological risk in the biomedical field and 412 workers without risk (RO group) showed a prevalence of $\mathrm{HBV}$ infection in 10.0 percent of these [8.8\% had positive HBV antibodies (108), $1.1 \%$ positive HBs antigen (14 subjects) and 0.2 percent ( 3 subjects) positive $\mathrm{HB}$ enveloped (HBe) antigen]; only 22.1 percent of subjects with positive antibodies or antigens remembered being $H B V$ infected.

Prevalences of HBV infection were not significantly different by sex. In contrast, aging appeared to significantly increase the infection rate $(p<0.001)$.

Furthermore, significant differences in the prevalence of $\mathrm{HBV}$ infection were not observed among risk groups. On the other hand, excluding vaccinated (333) and positive $\mathrm{HBs}$ antigen subjects, the prevalence of $\mathrm{HBV}$ infection significantly increased in intermediate and high risk groups compared with the presumably not exposed group (R2 vs R0: $p<0.025$; R3 vs R0: $p<0.001$ ) and low risk group ( $\mathrm{R} 2$ vs $\mathrm{R} 1: p<0.05$; $\mathrm{R} 3$ vs $\mathrm{R} 1: p<0.001$ ). In addition, significant prevalence was observed in the high vs intermediate risk group $(p<0.05)$. Table 2 summarizes the immunological status of the population investigated.

Among subjects exposed to continuous biological risk (Table 3), only surgeons showed a significantly higher prevalence of positive $\mathrm{HBV}$ antibodies than the presumably not exposed group ( $p<0.05$ ). Excluding nonsusceptible subjects (see above), the prevalence of positive antibodies in surgeons showed a significant increase $(p<0.001)$, and appeared significantly higher than 
Table 2. Prevalence of HBV infection according to sex, risk group and age

\begin{tabular}{|c|c|c|c|c|}
\hline & Negative & $\begin{array}{c}\text { Positive } \\
\text { HBV antibodies }\end{array}$ & $\begin{array}{c}\text { Positive } \\
\text { HBs antigen }\end{array}$ & $\begin{array}{l}\text { Positive in susceptible population } \\
\text { (excluding vaccinated subjects } \\
\text { and positive HBs antigen)' }\end{array}$ \\
\hline & $\%$ & $\%$ & $\%$ & $\%$ \\
\hline Total & 62.7 & 8.8 & 1.1 & 12.2 \\
\hline Males & 68.1 & 9.9 & 1.4 & 12.4 \\
\hline Females & 52.1 & 6.8 & 0.7 & 11.5 \\
\hline Ro & 89.1 & 8.5 & 0.2 & 8.9 \\
\hline $\mathrm{R} 1$ & 77.9 & 6.5 & 1.5 & 7.6 \\
\hline $\mathrm{R} 2$ & 46.2 & 8.3 & 1.9 & $14.8 * * *$ \\
\hline R3 & 26.0 & 12.8 & 1.3 & $31.9 *, * * * * *$ \\
\hline$\leq 40 \mathrm{yr}$ & 54.6 & 4.1 & 1.0 & 6.9 \\
\hline$>40 \mathrm{yr}$ & 70.8 & $13.5^{\#}$ & 1.3 & $15.8^{\#}$ \\
\hline
\end{tabular}

Legend: for abbreviation see Table $1 ;{ }^{*}<0.001$ with respect to subjects less than $40 \mathrm{yr}$ of age: * $<0.05$ or more with the respect to the $\mathrm{R} 0$ group; ${ }^{* *} p<0.05$ or more with the respect to the $\mathrm{R} 1$ group; $* * * 0<0.05$ or more with respect to the $\mathrm{R} 2$ group. $\chi^{2}$ distribution with Yates correction. 'Subjects with positive HBV antibodies in susceptible population were determined. Subtracted vaccinated and positive HBs antigen subjects from the total.

Table 3. Prevalence of HBV infection in subjects exposed to major biological risk (surgeons, physicians and employed in biochemical and microbiological laboratories). In brackets (column of infection) is shown the percentage of HBs antigen positive subjects

\begin{tabular}{lccc}
\hline & Negative & Infection & $\begin{array}{c}\text { Positive in susceptible population } \\
\text { (excluding vaccinated subjects } \\
\text { and positive HBs antigen) }\end{array}$ \\
\hline Controls & $\%$ & $\%$ & $\%$ \\
Surgeons & 89.1 & $8.5(0.2)$ & 9.2 \\
Physicians & 23.3 & $14.0(1.7)^{* * *}$ & $40.3 * * * * * * *$ \\
Analytical laboratory workers & 50.7 & $7.9(0.7)$ & 17.4 \\
- & 51.5 & $6.4(2.5)$ & -
\end{tabular}

Legend: $p<0.05$ or more with the respect to *Physicians, **Analytical laboratory workers or ****Controls $\left(\chi^{2}\right.$ distribution with Yates correction). For explanation on susceptible subjects, see Table 2.

that in physicians $(\mathrm{p}<0.05)$ and analytical laboratory workers $(p<0.005)$.

\section{Discussion}

The immunological condition preventing HBV infection was investigated in a population exposed to different degrees of biological hazard in Padua University. The aim was to evaluate the prevalence of HBV infection according to risk.

The prevalence of $\mathrm{HBV}$ infection appeared similar (8.8 percent of positive anti-HBc IgG, 1.1 percent of positive HBs antigen) to that published on the Northern and Central Italy population ( 9.7 percent $)^{13 !}$. Seroprevalence related to the risk is available in different studies but surgeons appeared more susceptible to acquiring the disease from percutaneous exposure" ${ }^{y}$. On the other hand, the risk is low for dental hygienists ${ }^{11}$, personnel of children's hospitals ${ }^{4}$ and analytical laboratory workers ${ }^{14}$. In addition, the prevalence of HBs antigen positive subjects is similar to that of $\mathrm{HCV}^{15}$.

Our results show that the prevalence of $\mathrm{HBV}$ infection was apparently unrelated to the risk; on the other hand, considering the susceptible population only (excluding non-susceptible subjects), a significant difference was observed in intermediate and high risk groups when compared with others. In addition, the highest risk group showed a significant increase in seroprevalence compared with the intermediate one. Frequency and conditions of contact with biological materials increase the possibility that the dose and serum viral concentration after repeated 
parenteral or percutaneous contamination reach an infectious level ${ }^{8}$. Indeed surgeons showed the highest seroprevalence among the susceptible subjects, according to Patz and Jodrey ${ }^{9)}$.

As stated in the introduction, the study of the casuistry fails to evaluate the immunological conditions when starting the current job career; this depending on the fact that any evaluation was done in the past. Anyway, even assuming that $\mathrm{HBs}$ antigen positive subjects were infected in infancy, they represent a small number. In addition, few subjects $(22.1 \%)$ with $\mathrm{HBV}$ positive antibodies remembered the disease.

In conclusion, the results show that: 1$)$ the population studied had, on the whole, low prevalence of HBV infection ( 8.8 percent of positive HBV antibodies, and 1.1 percent of positive HBs antigen); 2) age, but not sex appeared significantly correlated with the possibility of HBV infection; 3) intermediate and high risk groups showed a significant increase in the prevalence of $\mathrm{HBV}$ infection among susceptible subjects; surgeons had a significantly higher risk of $\mathrm{HBV}$ infection than physicians and analytical laboratory workers.

Acknowledgments: The authors are grateful to Rossella Zorzan, Caterina Zecchin, Bruna Vettorato and Carmen Garbo for the help in data collection, to Prof. Franco Bui for permission to use data on subjects who submitted to radioprotection surveillance and to the Microbiological Service of Padua Hospital (Chief: Prof. G.A. Meloni) for hepatitis markers determination.

\section{References}

1) Dobloug JH, Gerner NW, Hurlen B, Bruun JN, Skaug $\mathrm{K}$. HIV and hepatitis $\mathrm{B}$ infection in an international cohort of dental hygienists. Scand J Dent Res 1988; 96: 448-450.

2) Schlech WF. The risk of infection in anaesthetic practice. Can J Anaesth 1988; 35: S46-51.

3) Livengood JR, Miller GE, Coulter D, Foster LR. Hepatitis B and workers in institutions for the mentally retarded: risk of infection for staff in patient care. Am
J Prev Med 1989; 5: 170-174.

4) Hicks RA, Cullen JW, Jackson MA, Burry VF. Workrelated risk factors for hepatitis $B$ virus infection in personnel of children's hospital. Clin Pediatr 198928 : 245-250.

5) Hadler SC. Hepatitis B virus infection and health care workers. Vaccine 1990; 8 (suppl.): S24-S28.

6) Evans MR, Henderson DK, Bennet JE. Potential for laboratory exposures to biohazardous agents found in blood. Am J Public Health 1990; 80: 423-427.

7) Hewitt JB, Misner ST, Levin PF. Health hazards of nursing: identifying workplace hazards and reducing risks. AWHONNS Clin Issues Perinat Womens Health Nurs 1993; 4: 320-327.

8) Lanphear BP. Trends and patterns in the transmission of bloodborne pathogens to health care workers. Epidemiol Rev 1994; 16: 437-450.

9) Patz JA, Jodrey D. Occupational health in surgery: risks extend beyond the operating room. Aust NZ J Surg 1995; 65: 627-629.

10) Jackson LA, Stewart LK, Solomon SL, et al. Risk of infection with hepatitis $\mathrm{A}, \mathrm{B}$ or $\mathrm{C}$, cytomegalovirus, varicella or measles among child care providers. Pediatr Infect Dis J 1996; 15: 584-589.

11) Djeriri K, Fontana L, Laurichesse $H$, el al. Sćroprévalence des marqueurs des hépatites virales A, $\mathrm{B}$ et $\mathrm{C}$, parmi le personnel hospitalier du centre hospitalo-universitaire de Clermont-Ferrand. Presse Med 1996; 25: 145-150 (in French).

12) Mele A, Stroffolini T, Pasquini P. Integrated epidemiological system for acute viral hepatitis (SEIEVA). Report 1985-1994. Rapporti ISTISAN, ISSN 1123-3117, Roma, Italy, 1996.

13) D'Amelio R, Matricardi PM, Biselli R, et al. Changing epidemiology of hepatitis $B$ in Italy: public health implications. Am J Epidemiol 1992; 135: 1012-1028.

14) Sosnierz. L. Occurrence of HBs antigen and anti-HBs antibodies in analytical laboratory workers in Warsaw. Pol Tyg Lek 1989; 44: 383-386 (in Polish).

15) Trevisan A, Bicciato F, Fanelli G, Stocco E, Paruzzolo $P$. Risk of hepatitis $C$ virus infection in a population exposed to biological materials. Am J Ind Med 1999; 35: 532-535. 